DESIGN AND

\section{MANUFACTURING OF AN OPTIMIZED MOULD INSERT BY DMLS TECHNOLOGY}

TOMAS CORANIC

Department of Design and Monitoring of Technical Systems, Faculty of Manufacturing Technologies with a seat in Presov, Technical University of Kosice, Presov Slovak republic

DOI: 10.17973/MMSJ.2021_12_2021186

tomas.coranic@tuke.sk

Utilization of the DMLS technology in manufacturing of tools and moulds designed for injection and casting ranks among significant possibilities of use. The main advantage in case of DMLS in comparison to conventional methods rests in the fact that manufacturing time does not depend on geometrical complexity of shaping part of the mould. In case of low volume or prototype moulds it is advantageous to use a concept of combination of shaping intermediate pieces inserted in universal frames and as material the DM 20 alloy on bronze basis the service life of which in case of such application is several thousand pieces.

KEYWORDS

additive manufacturing, DMLS, topology, optimization.

\section{INTRODUCTION}

Rapid Tooling - to present simple explanation of the term Rapid Tooling (RT) it is inevitable to provide basic categorization to direct and indirect methods. In case of direct methods referred to as Direct Rapid Tooling the DMLS technology allows manufacturing of directly final shape of required tool on the basis of the 3D data layer-by-layer. The tools manufactured by the aforementioned method require additional conventional machining or further heat treatment. In case of indirect methods referred to as Indirect Rapid Tooling (IRT) is by means of additive manufacturing made socalled master model which serves for derivation of the final mould shape. In practice it means that the final quality and accuracy of the mould thus directly depends on the master model [Rozvany 2009, Gibson 2014].

Hybrid concept - in case of this concept a possibility of combination of additive manufacturing with conventional manufacturing procedures is used. In mould design there is frequent occurrence of a situation in case of which one part of the mould, usually the front part of the cast, is less complicated as to the shape and the other one contains diverse supporting elements such as ribs and reinforcement and thus is more complicated as to the shape. In these situations, from point of view of economy and time it is advantageous to use the combination in case of which a simpler front part is manufactured by classical machining methods and when manufacturing of the injection mould core it is advisable to employ the DMLS technology. Or in case of relatively small areas being complicated as to the shape and occurring inside the mould cavity it is recommended to manufacture just shaping intermediate pieces corresponding to these areas and insert them into the milled channels in the mould cavity [Sigmund 2013, Strano 2013, Mascenik 2019].

Conformal cooling of moulds - to obtain high quality parts manufactured by injection or casting a mould structure represents rather significant factor, specifically a design of its core and cavity in case of which cooling plays an important role. Cooling is an important factor even in case of generating of final price and competitiveness of the company in the market as in the manufacturing process it takes up half of the time of a single cycle. Technical advancement and availability of modern materials for the DMLS technology made such a huge progress that at present it allows manufacturing of the moulds with socalled conformal cooling in case of which cooling channels are manufactured directly as part of the mould and are not additionally drilled and thus perfectly copy the shape of a cast or of a formed piece. In use of classical cooling channels which are manufactured by drilling and by consequent blanking off the holes to achieve required direction of the flow of cooling medium the problem does not rest only in shape complexity of the mould but also further aspects such as ejectors or disengaging intermediate piece which can occur in the areas needed for cooling supply and achievement of optimal cooling is rather difficult even impossible [Brackett 2011, SochalskiKolubs 2015, Kascak 2021]

Design of conformal cooling follows certain principles. Basic input parameters are thickness of the model wall, cross section of cooling channel, distance of the model wall from the centre of the cooling channel and pitch between the channels.

An independent parameter which cannot be influenced by a design engineer is the thickness of model wall and the dimension is specified by the customer. The cross section of the cooling channel depends on the thickness of the model wall in case of which it is possible to select within the given range with regards to structural design of the model. Consequently, other parameters depend on cross section within the given range. If it was inevitable to use different geometrical shape of the cooling channel which would meet the criteria of the particular application better, it would be necessary to observe the circumference of the respective circular cross section and to design other parameters in a similar way [Kianian 2012, Gibson 2014].

\section{OPTIMIZATION}

The optimization process is based on such adjustment which assures optimization of a specific set of defined parameters with regards to required limitations. One of the most common objectives of topology is to minimize costs when reaching maximal effectiveness. According to other definition, the optimization can be defined as selection of the best possible design within the framework of available options [Rozvany 2009, Deshpande 2001, Bun 2018].

\subsection{Size Optimization}

By means of size optimization ideal parameters of the component are defined which include, for instance, cross section, dimensions, and wall thickness and material values. It is used for determination of basic dimensions so that performance or strength objectives are met with taking into consideration loads which shall influence the part or component during its life cycle. In general, the optimization is used in the phase with already defined initial requirements regarding component geometry, i.e., when optimization of shape and topology is carried out because prior to triggering the defined initial geometry is required. [Deschpande 2001, Brackett 2011, Sochalski-Kolubs 2015 , Ivanov 2018].

\subsection{Size Optimization}

Shape optimization contains definition of parameters of components such as values of material, dimensions of cross section and thickness. Shape optimization is carried out after 
optimization of topology and topology optimization is applied when a basic concept of material distribution is being elaborated and consequently the concept is adjusted and improved by shape optimization in order to reach more natural and smooth surfaces. The areas are usually defined as walls or shapes. It is the second step in the process of design of structural optimization. During shape optimization the external limitations of the structure are adjusted so that the problems of optimization are solved. The shape is designed by means of finite element analysis and through definition of a grid [Chu 2008, Yadroitsev 2014, Tang 2014, Mascenik 2018, Majernik 2021].

\subsection{Structural Optimization of Topology}

Parameters dealing with structural problem of structural optimization are objective variable and structural limitations of the design. In general, the problem of optimization is defined as minimization or maximization of objective function which is exposed to geometrical limitations. The following parameters can be defined as target function or limiting conditions:

- manufacturing or material costs,

- structural weight or volume,

- local structural response such as tension, stress or shift of the individual points,

- maximal stress or maximal shift of the structure,

- intensity factor,

- overall structural properties such as toughness, loading, vibrations, dynamic response, etc.

Geometrical limitations can thus be defined as follows:

- physical limitations,

- limitations of manufacturing possibilities,

- manufacturing,

- dimensional limitations.

Proposed structural variables are determined in the optimization process. The use of numerical procedures has been increasingly developing in the topology optimization along with progress in technology and in computational technique. In case of the use of numerical approach the design optimization begins with definition of material which is subjected to external load. In order to achieve the best possible structural solution, the optimizing algorithm consequently continues with removal of unloaded material [Evans 2001, Hiller 2009, Brackett 2011, Cooper 2012]. In the course of the optimization process there is a tendency of increase of the problem complexity. This type of the problem represents one of the most complicated issues in structural mechanics [Cooper 2012, Rafi 2013].

\section{GRID STRUCTURES}

As the world becomes more competitive place, the industrial sectors use every single opportunity to keep ahead of competitors. Economic and environmental needs force manufacturing companies to reduce costs and waste and to increase effectiveness. Modern solutions and approaches must be thus implemented so that any possible progress is made. Increasing need of energy saving intensifies the need to manufacture light and resistant parts. Advantages of reduction of weights are significant in all industrial segments. In case of aviation and automotive industry the reduction of weight may contribute to saving of fuel costs. The studies have proved that reduction of weight by $10 \%$ may save approximately $6-8 \%$ of fuel consumption. By means of application in case of manufacturing of moulds material and energy costs are reduced. An important aspect is to manufacture light parts disposing of good mechanical properties. Grid structure represents a suitable solution for reaching this aim. High resistance along with low weight represent thus a significant advantage of grid structure. Grid structures can be used to achieve required properties and functionality with simultaneous weight reduction. The concept of material distribution rests in the theory of placing the material only to the areas which can bear the load and which need it. The sphere of research related to the structures acquires higher attention mainly due to their advantages contrary to stochaic structures in case of manufacturing of light and extremely solid parts [Gibson 2005, Kooistra 2007, Gibson 2014, , Rashed 2016]. A term "cell" comes from the Latin word "cella" which means a slight separation of closed area. Clusters or groups of cells then form a cell structure. The most frequent cell structures which are common in everyday life are, for instance, wood, cork or sponge. Some of the structures have existed in the form of natural material for ages and people would extract and use them in a number of ways. For instance, cork has been used as a lid of bottles since the Roman Empire. Gradual development can nowadays lead to formation of similar cell structures in order to produce light and resistant structures [Zhu 1997, Mital 2021].

- Grid structures in the nature - a number of materials exist in the nature containing structures of grid character. The materials are significant in case of light structures. Natural tubular structures frequently occur in the form of honey board or foam core serving as a support for thicker external shell which increases resistance of entire case against local disruption. These materials can serve as references in case of formation of grid structures for light materials which should dispose of high strength. Further natural example is hexagonal grid arrangement of structure in case of which certain similarities to cell structures of wood can be observed. Toughness and strength according to the type of wood depends on its density and direction of loading. Yet its resistance to disturbance is higher if the direction of the loading is identical with direction of wood growth in comparison to its perpendicular application. For example, structure of trabecular bone is worth mentioning. The bone structure is adjusted to acting loadings and its growth is thus reaction to size and direction of acting loading [Rozvany 2009, Zhang 2015].

- Stochastic and periodical structures - these materials can be classified as stochastic and periodic structures. Materials which are characterized by a unit cell that can be folded and repeated are referred to as periodic materials and the cell materials not possible to be characterized by a single cell area are the stochastic ones [Zhu 1997, Koistra 2007].

- Prismatic and grid structures - refer to two types of defined periodic cell structures. The first group comprises of periodical structures in case of which the cells are repeatedly folded in two directions and they are also known as prism cell materials. The example of prismatic cell material is a cratelike structure which disposes of high toughness and relatively low weight structure. The second type refers to periodic structures which are formed as a three-dimensional periodicity of a unit cell. In practice it means that the structure is formed as a unit cell 
which is folded in three axes. These structures are frequently referred to as grid materials. The grid structure is thus an example of the cell structure [Gibson 2005, Ponader 2008, Tang 2014, Mun 2015, Thompson 2016].

\section{DESIGN AND MANUFACTURING}

In the practical part, the publication deals with the application of optimization of structural topology in manufacturing of the shaping intermediate piece of injection mould by means of the additive manufacturing. The shaping intermediate piece is designed for manufacturing of the plastic part shown in figure 1 by the technology of plastic injection.

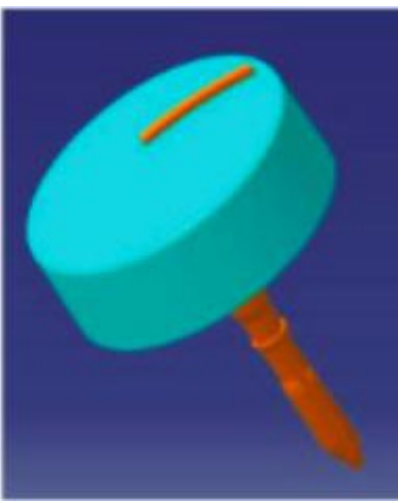

Figure 1. Moulded plastic part

Figure 2 shows the designed shaping intermediate piece with the conformal cooling which was manufactured by the DMLS technology.

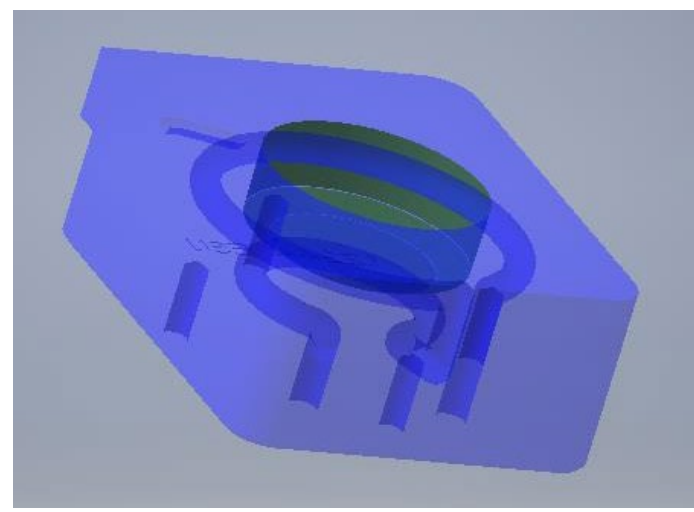

Figure 2. Model of shaping intermediate piece with conformal cooling

For the optimization of the shaping intermediate piece, the program Netfabb by the company of Autodesk was applied. The proposed and examined alternative was the structure based on the elements in the star shape. The section of the shaping intermediate piece with the inner structure in the star shape is shown in figure 3 . The structure was designed with regards to functional parts in case of which full volume was preserved and stepping in case of each axis was of $5 \mathrm{~mm}$. The thickness of each element was of $4 \mathrm{~mm}$. In the bottom part the perforating hole was produced to remove excessive dust after completion of manufacturing.

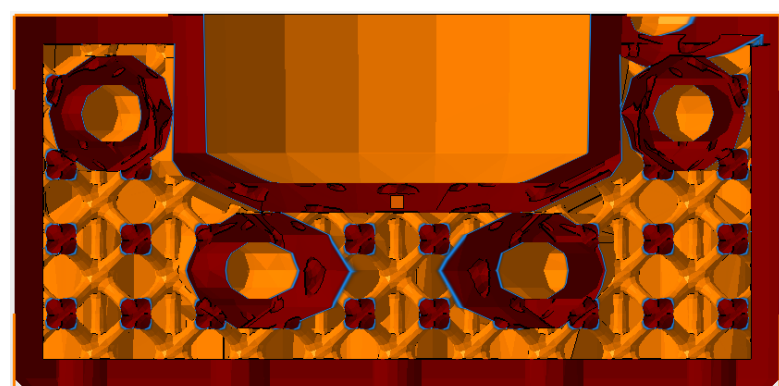

Figure 3. Section through shaping intermediate piece with inner structure in the star shape

\subsection{Preparation of Manufacturing}

The first step includes conversion of voluminous body to the "stl." format which represents a net model and the net itself consists of triangles and describes only the areas of the model. The view of the model is shown in figure 4 with the original model situated on the left and with the model with the inner structure situated on the right.

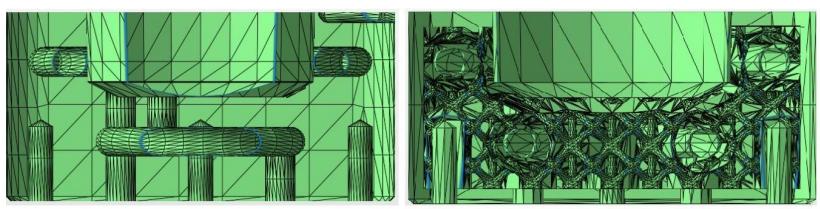

Figure 4. STL model of the original and modified shaping intermediate piece

As the model with the inner topology contains more shaping areas, a rapid increase was observed in number of the triangles inevitable for description of these areas from the original 7726 to 364374 with the preservation of the identical accuracy. Consequently, both models were controlled from the point of view of the net closing. Both shaping intermediate pieces were centred in the middle of working area of the machine EOSINT M280 and in the " $\mathrm{z}$ " axis the stepping was preserved to allow placement of the supporting structure for easier removal of the final product from the machine after completion of the manufacturing. Apart from the " $\mathrm{z}$ " axis it was also inevitable to extend the supporting structure in the projecting part in the corner of the shaping intermediate piece as it was situated outside the model and during manufacturing it would not be self-supporting. Figure 5 shows the extension of the supporting structure applicable for both proposed alternatives. The overall volume of material used for the application of supporting structures was in the height of $3.25 \mathrm{~cm} 3$ which with the material density of $8.1 \mathrm{~g} . \mathrm{cm}^{-3}$ represents $26.325 \mathrm{~g}$ of material.

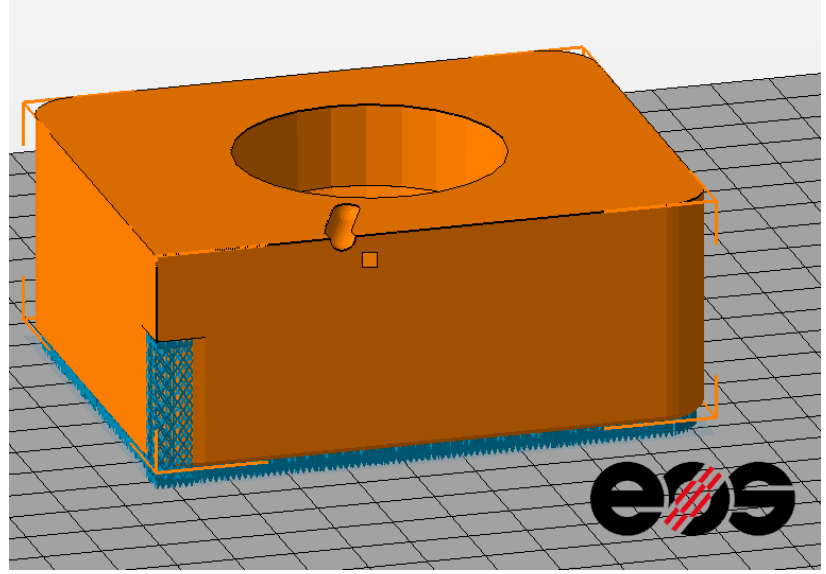

Figure 5. Application of supporting structures 
Standard parameters by the company of EOS with the height of layer of $50 \mu \mathrm{m}$ were selected for the manufacturing. The program recalculated the time inevitable for manufacturing and consumption of material. These parameters are shown in figures 73 and 74 . In case of the original monolithic shaping intermediate piece the calculated time was 51 hours and 8 minutes and 10 seconds with the inevitable material volume of $244.29 \mathrm{~cm} 3$ which according to material density refers to 1978.75g (Figure 6). In case of the shaping intermediate piece with the applied inner structure the time needed for manufacturing was reduced to 31 hours and 30 minutes and 27 seconds and consumption of material dropped to $146.15 \mathrm{~cm} 3$ which refers to $1183.82 \mathrm{~g}$ of basic powder material (Figure 7).

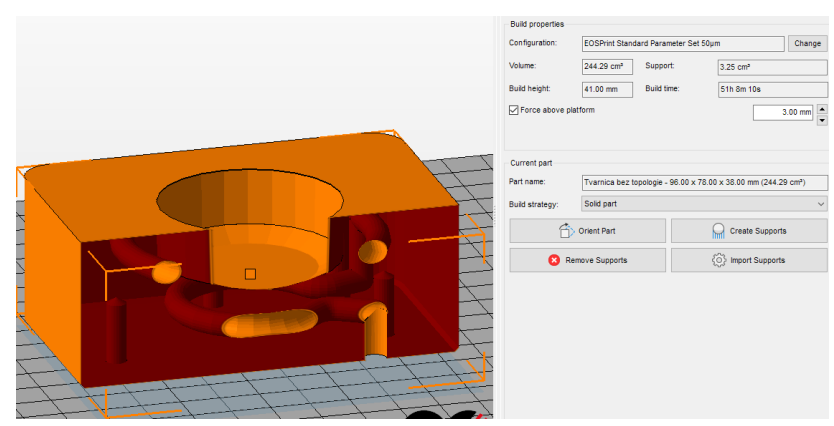

Figure 6. Parameters of manufacturing of the original shaping intermediate piece

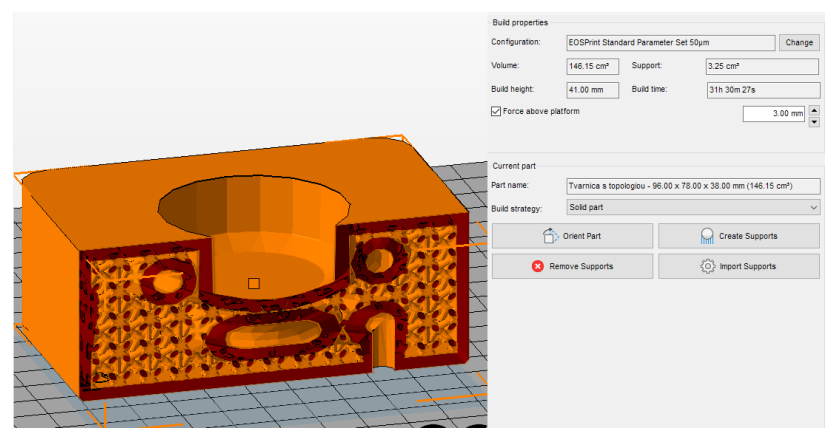

Figure 7. Parameters of manufacturing of the shaping intermediate piece with the inner structure

When the pre-manufacturing settings had been completed, the manufacturing of the shaping intermediate piece was simulated as it is shown in figure 8 in which the supporting structures is red and the green colour refers to the layer being actually manufactured. Eight hundred twenty (820) layers must be manufactured in total with thickness of $50 \mu \mathrm{m}$ which represents the height of $41 \mathrm{~mm}$, and $38 \mathrm{~mm}$ refer to the height of the shaping intermediate piece itself, and $3 \mathrm{~mm}$ were defined as supporting structure situated in the bottom part to provide easier removal of the final shaping intermediate piece from the machine chamber after completion of manufacturing.

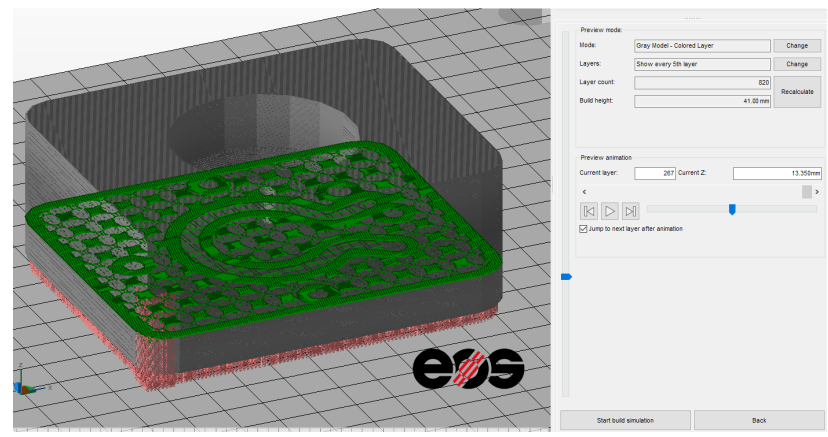

Figure 8. Simulation of process of manufacturing of the shaping intermediate piece with the inner structure by the DMLS technology

\section{CONCLUSIONS}

After verification of the results from the point of view of manufacturing and of the application itself was the alternative in question analysed from the economic point of view as it represents a significant factor for permanent sustainability and competitiveness of the manufacturing companies. Through the reduction and redistribution of material the reduction of financial burden by $38.5 \%$ was reached. On the basis of the information a conclusion can be made. The correct application of optimization of structural topology and observation of basic principles and restrictions applicable in designing of the components manufactured by the DMLS technology may result in effective and economic results with the preservation of the requirements related to the component.

\section{ACKNOWLEDGMENTS}

This article has been prepared within the projects KEGA 017TUKE-4/2021 and VEGA 1/0116/20.

\section{REFERENCES}

[Brackett 2011] Brackett, D., Ashcroft, I., Hague, R. Topology optimization for additive manufacturing. In: Proceedings of the Solid Freeform Fabrication Symposium, Austin, TX, 2011.

[Bun 2012] Bun P., Trojanowska J., Ivanov V., Pavlenko I. The Use of Virtual Reality Training Application to Increase the Effectiveness of Workshops in the Field of Lean Manufacturing. In: Proc. of the 4th Int. Conf. of the Virtual and Augmented Reality in Education VARE 2018, Bruzzone A.G., Ginters E., Gonzalez Mendivil E. et al. (eds.), 2018, pp. 65-71.

[Cooper 2012] Cooper, D.E., Stanford, M., Kibble, K.A., Gibbons, G.J. Additive manufacturing for product improvement at red bull technology. Materials \& Design, 2012, Vol. 41, pp. 226-230.

[Coranic 2018] Coranic, T., Gaspar, S., Pasko, J. Structural modification impact analysis of selected components od shielding equipment using rapid prototyping technology. MM Science Journal, 2018, Vol. March, pp. 2183-2187. ISSN 1803-1269.

[Deshpande 2001] Deshpande, V., Ashby, M., Fleck, N. Foam topology: bending versus stretching dominated architectures. Acta Materialia, 2001, Vol. 49, No. 6, 1035-1040.

[Evans 2001] Evans, A.G., Hutchinson, J.W., Fleck, N., Ashby, M., Wadley, H. The topological design of multifunctional cellular metals. Progress in Materials Science, 2001, Vol. 46, No. 3, pp. 309-327.

[Gibson 2005] Gibson, L.J. Biomechanics of cellular solids. Journal of biomechanics, 2005, Vol. 38, No. 3, pp. 377-399.

[Gibson 2014] Gibson, I., Rosen, D. W., Stucker, B. Additive manufacturing technologies: 3D printing, rapid prototyping, and direct digital manufacturing. Springer-New York, 2014, 498 p. ISBN 978-1-49392112-6.

[Hiller 2009] Hiller, J. D., Lipson, H. Stl 2.0: a proposal for a universal multi-material additive manufacturing file format. In: Proceedings of the Solid Freeform Fabrication Symposium, Austin, TX, Vol. 1, 2009.

[Chu 2008] Chu, C., Graf, G., Rosen, D.W. Design for additive manufacturing of cellular structures. ComputerAided Design and Applications, 2008, Vol. 5, No. 5, pp. 686-696. 
[ISO 2015] International Organization for Standardization (ISO) \& American Society for Testing and Materials (ASTM). (2015). Additive manufacturing - General principles - Terminology (ISO/ASTM 52900:2015).

[Ivanov 2018] Ivanov V. et al. Using the Augmented Reality for Training Engineering Students. In: Proc. of the 4th Int. Conf. of the Virtual and Augmented Reality in Education VARE 2018, Bruzzone A.G., Ginters E., Gonzalez Mendivil E. et al. (eds.), 2018, pp. 57-64.

[Kascak 2021] Kascak, J. et al. Design of an Atypical Construction of Equipment for Additive Manufacturing with a Conceptual Solution of a Printhead Intended for the Use of Recycled Plastic Materials. Appl. Sci., 2021, Vol. 11, p. 2928.

[Kianian 2012] Kianian, B., Nopparat, N. Resource consumption of additive manufacturing technology. Blekinge Institute of Technology, Blekinge, Sweden, 2012.

[Kooistra 2007] Koistra, G. W., Wadley, H. N. Lattice truss structures from expanded metal sheet. Materials \& Design, 2012, Vol. 28, No. 2, pp. 507-514.

[Majernik 2021] Majernik, J., Gaspar, S., Husar, J., Pasko, J., Kolinsky, J. Research and Evaluation of the Influence of the Construction of the Gate and the Influence of the Piston Velocity on the Distribution of Gases into the Volume of the Casting. Materials, 2021, Vol. 14, p. 2264.

[Mascenik 2018] Mascenik, J., Pavlenko, S. Innovative broad Spectrum testing and monitoring of belt transmissions. MM Science Journal, 2018, Vol. Dec., pp. 2706-2709.

[Mascenik 2019] Mascenik, J. Implementation of the designed program for calculation and check of chain gears. MM Science Journal, 2019, Vol. Dec., pp. 34313434.

[Mital 2021] Mital, G., Spisak E., Mulidran, P., Kascak, L., Jezny, T. 3D evaluation of the topography of the surface by abrasive water jet machining technology. MM Science Journal, 2021, Vol. Oct., pp. 4847-4852.

[Mun 2015] Mun, J., Yun, B.G., Ju, J., Chang, B.M. Indirect additive manufacturing based casting of a periodic $3 d$ celulular metal-flow simulation of molten aluminum alloy. Journal of Manufacturing Processes, 2015, Vol. 17, pp. 28-40.

[Ponader 2008] Ponader, S. et al. Effects of topographical surface modifications of electron beam melted ti$6 a l-4 v$ titanium on human fetal osteoblasts. Journal of biomedical materials research Part A, 2008, Vol. 84, No. 4, pp. 1111-1119.

[Rafi 2013] Rafi, H.K., Karthik, N.V., Gong, H., Starr, T.L., Stucker, B.E. Microstructures and Mechanical Properties of Parts Fabricated by Selective Laser Melting and Electron Beam Melting. Journal of
Materials Engineering and Performance, 2013, Vol. 22, No. 12, pp. 3872-3883.

[Rashed 2016] Rashed, M., Ashraf, M., Mines, R., Hazell, P.J. Metallic microlattice materials: A current state of the art on manufacturing, mechanical properties and applications. Journal of Materials Engineering and Performance, 2016, Vol. 95, pp. 518-533.

[Rozvany 2009] Rozvany, G. A critical review of established methods of structural topology optimization. Structural and Multidisciplinary Optimization, 2009, Vol. 37, No. 3, pp. 217-237.

[Sigmund 2013] Sigmund, O. Maute, K. Topology optimization approaches. Structural and Multidisciplinary Optimization, 2013, Vol. 48, No. 6, pp. 1031-1055.

[Sochalski-Kolbus 2015] Sochalski-Kolbus, L.M. et al. Comparison of residual stresses in Inconel 718 simple parts made by Electron Beam Melting and Direct Laser Metal Sintering. Metallurgical and materials transactions, 2015, Vol. 46, No. 3, pp. 1419-1432.

[Strano 2013] Strano, G., Hao, L., Everson, R.M., Evans, K.E. A new approach to the design and optimisation of support structures in additive manufacturing. The International Journal of Advanced Manufacturing Technology, 2013, Vol. 66, pp. 1247-1254.

[Tang 2014] Tang, Y., Hascoet, J.Y., Zhao, Y.F. Integration of topological and functional optimization in design for additive manufacturing. In: 12th Biennial Conf. on Engineering Systems Design and Analysis ESDA 2014. Copenhagen, Denmark, July 25-27, 2014, ASME, 2014. ISBN 9780791845837.

[Thompson 2016] Thompson, M.K. et al. Design for additive manufacturing: Trends, opportunities, considerations, and constraints. CIRP AnnalsManufacturing Technology, 2016, Vol. 65, No. 2, pp. 737-760.

[Yadroitsev 2014] Yadroitsev, I., Krakhmalev, P., Yadroitsava, I. Hierarchical design principles of selective laser melting for high quality metallic objects. Additive Manufacturing, 2014, Vol. 7, pp. 45-56. doi:10.1016/j.addma.2014.12.007.

[Zhang 2015] Zhang, P. et al. To Efficient design-optimization of variable-density hexagonal cellular structure by additive manufacturing: theory and validation. Journal of Manufacturing Science and Engineering, 2015, Vol. 137, No. 2.

[Zhu 1997] Zhu, H., Knott, J., Mills, N. Analysis of the elastic properties of open-cell foams with tetrakaidecahedral cells. Journal of the Mechanics and Physics of Solids, 1997, Vol. 45, No. 3, pp. 319-343.

\section{CONTACTS}

M.Sc. Tomas Coranic, PhD.

Department of Design and Monitoring of Technical Systems, Faculty of Manufacturing Technologies with a seat in Presov, Technical University of Kosice, Presov, Slovak Republic

Bayerova 1, Presov, 080 01, Slovak Republic

+421 51772 6315, tomas.coranic@tuke.sk,www.tuke.sk 